\title{
Estimation of Effective Lens Position Using a Method Independent of Preoperative Keratometry Readings
}

\author{
I. Dooley \\ Waterford Regional Hospital \\ S. Charalampidou \\ Waterford Regional Hospital \\ John Nolan \\ Waterford Institute of Technology
}

See next page for additional authors

Follow this and additional works at: https://arrow.tudublin.ie/otpomart

Part of the Optometry Commons

\section{Recommended Citation}

Dooley, I., Charalampidou, S., Nolan, J., Loughman, J., Molloy, L., Beatty, S.: Estimation of Effective Lens Position Using a Method Independent of Preoperative Keratometry Readings. Journal of Cataract and Refractive Surgery, Vol.37, no.3, pp.506-12. 2011. doi:10.1016/j.jcrs.2010.09.027.

This Article is brought to you for free and open access by ARROW@TU Dublin. It has been accepted for inclusion in Articles by an authorized administrator of ARROW@TU Dublin. For more information, please contact arrow.admin@tudublin.ie, aisling.coyne@tudublin.ie, gerard.connolly@tudublin.ie.

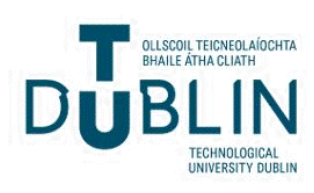


Authors

I. Dooley, S. Charalampidou, John Nolan, James Loughman, Molly Breen, and Stephen Beatty

This article is available at ARROW@TU Dublin: https://arrow.tudublin.ie/otpomart/17 


\section{Elsevier Editorial System(tm) for Journal of Cataract \& Refractive Surgery}

Manuscript Draft

Manuscript Number:

Title: Estimation of effective lens position using a method independent of preoperative keratometry readings

Article Type: Full Length Article

Section/Category: Cataract

Keywords: Effective lens position; Scheimpflug Pentacam; Holladay; SRK/T; phacoemulsification cataract surgery.

Corresponding Author: Mr Ian John Dooley, MRCOphth., MSc.

Corresponding Author's Institution: Waterford Regional Hospital

First Author: Ian John Dooley, MRCOphth., MSc.

Order of Authors: Ian John Dooley, MRCOphth., MSc.; Sonia Charalampidou, MRCOphth; John Nolan, PhD; James Loughman, PhD; Laura Molloy, BA; Stephen Beatty, FRCOphth, MD

Abstract: Purpose

To evaluate the validity of a keratometry-independent method of estimating effective lens position (ELP) prior to phacoemulsification cataract surgery.

Setting

Institute of Eye Surgery, Whitfield Clinic, Waterford, Ireland

Methods

The anterior chamber diameter (AGm) and corneal height (Hm) in 95 eyes (95 patients) scheduled for cataract surgery were measured with a rotating Scheimpflug camera. Hm and AGm were used to estimate the ELP in a keratometry-independent method (using the SRK/T [ELPrs] and Holladay 1 [ELPrh] formulae).

Results

The mean $( \pm$ SD) ELP was calculated using traditional (mean ELPs \pm SD: $5.59 \pm 0.52 \mathrm{~mm}$ and mean $\mathrm{ELPh} \pm \mathrm{SD}: 5.63 \pm 0.42 \mathrm{~mm}$ ) and keratometry-independent (mean ELPrs \pm SD: $5.55 \pm 0.42 \mathrm{~mm}$ and mean ELPrh \pm SD: $5.60 \pm 0.36 \mathrm{~mm}$ ) methods. Agreement between ELPs and ELPrs and between ELPh and ELPrh were represented by Bland Altman plots, with mean differences $( \pm 1.96$ SD; range; student's t-test) of $0.06 \mathrm{~mm}( \pm 0.65 \mathrm{~mm} ;-0.59$ to $+0.71 \mathrm{~mm} ; \mathrm{p}=0.08)$ in association with ELPrs and $-0.04 \mathrm{~mm}( \pm$ $0.39 \mathrm{~mm} ;-0.43$ to $+0.35 \mathrm{~mm} ; \mathrm{p}=0.08$ ) in association with ELPrh. The mean absolute error (MAE) for ELPs versus ELPrs estimation and for ELPh versus ELPrh estimation were $0.242 \pm 0.222 \mathrm{~mm}$ (range: 0.001 to $1.272 \mathrm{~mm}$ ) and $0.152 \pm 0.137 \mathrm{~mm}$ (range: 0.001 to $0.814 \mathrm{~mm}$ ), respectively.

\section{Conclusion}

This novel study confirms that this keratometry-independent ELP estimation method is comparable to traditional keratometry-dependent methods and may be useful in post-refractive surgery patients. 



\title{
Estimation of effective lens position using a method
} independent of preoperative keratometry readings

\author{
Authors \\ Dr. Ian Dooley, MRCOphth ${ }^{1,2}$ \\ Dr. Sofia Charalampidou, MRCPI, MRCOphth ${ }^{1,2}$ \\ Dr. John Nolan, $\mathrm{PhD}^{4}$ \\ Dr. James Loughman FAOI, $\mathrm{PhD}^{3}$ \\ Ms. Laura Molloy BA ${ }^{2}$ \\ Mr. Stephen Beatty, FRCOphth, MD ${ }^{1,2,4}$
}

\author{
Affiliations \\ 1. Department of Ophthalmology, Waterford Regional Hospital, Dunmore Road, \\ Waterford, Ireland \\ 2. Institute of Eye Surgery, Suite 14, Whitfield Clinic, Butlerstown North, Cork Road, \\ Waterford, Ireland \\ 3. Department of Optometry, School of Physics Dublin Institute of Technology, \\ Kevin Street, Dublin 8, Ireland. \\ 4. Waterford Institute of Technology, Cork Road, Waterford, Ireland.
}




\section{Running title}

Utilising Scheimpflug imaging to estimate effective lens position in a keratometryindependent fashion.

\section{Presentations}

This work has been presented at the Irish College of Ophthalmologist's annual meeting May 2010.

\section{Funding}

No author received any funding for this study.

\section{Declaration}

The authors declare that they have no conflict of interest.

\section{Keywords}

Effective lens position; Scheimpflug Pentacam; Holladay; SRK/T; phacoemulsification cataract surgery. 


\section{Correspondence}

Corresponding Author: Dr. Ian Dooley

Address: Department of Ophthalmology, Mater Misericordiae University Hospital, Eccles street, Dublin, Ireland; Institute of Eye Surgery, Suite 15, Whitfield Clinic, Cork Road, Waterford, Ireland.

Email: iandooley@eustace.net 


\section{Purpose}

To evaluate the validity of a keratometry-independent method of estimating effective lens position (ELP) prior to phacoemulsification cataract surgery.

\section{Setting \\ Institute of Eye Surgery, Whitfield Clinic, Waterford, Ireland}

\section{Methods}

The anterior chamber diameter $\left(\mathrm{AG}_{\mathrm{m}}\right)$ and corneal height $\left(\mathrm{H}_{\mathrm{m}}\right)$ in 95 eyes $(95$ patients) scheduled for cataract surgery were measured with a rotating Scheimpflug camera. $H_{m}$ and $A_{\mathrm{m}}$ were used to estimate the ELP in a keratometry-independent method (using the SRK/T $\left[\mathrm{ELP}_{\mathrm{rs}}\right]$ and Holladay $1\left[\mathrm{ELP}_{\mathrm{rh}}\right]$ formulae).

\section{Results}

The mean $( \pm \mathrm{SD})$ ELP was calculated using traditional (mean $\mathrm{ELP}_{\mathrm{s}} \pm \mathrm{SD}: 5.59 \pm 0.52$ $\mathrm{mm}$ and mean $\mathrm{ELP}_{\mathrm{h}} \pm \mathrm{SD}: 5.63 \pm 0.42 \mathrm{~mm}$ ) and keratometry-independent (mean $\mathrm{ELP}_{\mathrm{rs}} \pm \mathrm{SD}: 5.55 \pm 0.42 \mathrm{~mm}$ and mean $\left.\mathrm{ELP}_{\mathrm{rh}} \pm \mathrm{SD}: 5.60 \pm 0.36 \mathrm{~mm}\right)$ methods. Agreement between ELP $\mathrm{S}_{\mathrm{s}}$ and $\mathrm{ELP}_{\mathrm{rs}}$ and between $\mathrm{ELP}_{\mathrm{h}}$ and $\mathrm{ELP}_{\mathrm{rh}}$ were represented by Bland Altman plots, with mean differences ( $\pm 1.96 \mathrm{SD}$; range; student's t-test) of $0.06 \mathrm{~mm}( \pm 0.65 \mathrm{~mm} ;-0.59$ to $+0.71 \mathrm{~mm} ; \mathrm{p}=0.08)$ in association with $\mathrm{ELP}_{\mathrm{rs}}$ and $0.04 \mathrm{~mm}( \pm 0.39 \mathrm{~mm} ;-0.43$ to $+0.35 \mathrm{~mm} ; \mathrm{p}=0.08)$ in association with ELP $_{\mathrm{rh}}$. The mean absolute error $(\mathrm{MAE})$ for $\mathrm{ELP}_{\mathrm{s}}$ versus $\mathrm{ELP}_{\mathrm{rs}}$ estimation and for $\mathrm{ELP}_{\mathrm{h}}$ versus 
ELP $_{\text {rh }}$ estimation were $0.242 \pm 0.222 \mathrm{~mm}$ (range: 0.001 to $1.272 \mathrm{~mm}$ ) and $0.152 \pm$ $0.137 \mathrm{~mm}$ (range: 0.001 to $0.814 \mathrm{~mm}$ ), respectively.

\section{Conclusion}

This novel study confirms that this keratometry-independent ELP estimation method is comparable to traditional keratometry-dependent methods and may be useful in post-refractive surgery patients. 
As a result of improved predictability of refractive outcomes following cataract surgery, patients' expectations are high, and attaining precise postoperative refraction within $\pm 0.50 \mathrm{D}$ of target is a realistic goal of the conscientious cataract surgeon. The accuracy of predicting the necessary power for an intraocular lens (IOL) is dependent upon the accuracy of several preoperative measurements. ${ }^{1} 2$ These include, depending upon the formula used, some or all of the following: central corneal refractive power (keratometry readings); axial length (biometry); horizontal corneal diameter (horizontal white-to-white); anterior chamber depth (ACD); lenticular thickness; preoperative refraction; and the age of the patient. ${ }^{1-3}$

Definitions of ACD vary according to context and this should be acknowledged in any discussion of ACD. The clinical definition of ACD in the normal phakic eye is straightforward, and refers to the distance from the cornea to the anterior surface of the lens. Anatomically, ACD refers to the distance between the posterior surface of the cornea, but in an optical context (such as when discussing ACD in an IOL power formula) the distance is normally measured from the anterior surface of the cornea and includes the corneal thickness. This is justified, in part, by the position of the second principal plane of the cornea, which is close to the anterior surface (actually about $0.05 \mathrm{~mm}$ in front of the cornea). ${ }^{3}$

However, the end-point of the ACD distance is much more complex. Many formulae do not use the anterior surface of the IOL as the reference point, but rather the 'effective lens position' (ELP), defined as the effective distance from the anterior 
surface of the cornea to the lens plane as if the lens was of infinite thinness. The ELP may be back-calculated as the effective ACD 'predicting' the actual postoperative refraction on a given dataset. Hence, the ELP is formula-dependent and need not reflect the true ACD in the anatomical sense. This is the case for an ACD defined by the manufacturer on an IOL container along with the A-constant. The ACD in this context is most often based on the Binkhorst formula and cannot be taken to reflect the true postoperative lens position of the pseudophakic eye. ${ }^{3}$ For the sake of clarity we will, henceforth, refer to the postoperative ACD as the postoperative IOL position.

Models based on statistically analysed relationships between some or all of the previously mentioned preoperative measurements of the eye and the postoperative IOL position have been used to predict the ELP in the preoperative setting. Thus, estimation of ELP remains an empirical component to all ocular biometric formulae predicting refractive outcomes following cataract surgery, and different models for doing this are important determinants of the accuracy of different formulae for predicting refractive outcomes following cataract surgery. ${ }^{4}$ The predictability of ELP has improved over recent years, attributable to enhancements in the formulae used and the accuracy of the preoperative measurements of ocular biometric variables.

In 1975, Fyodorov derived an equation, ${ }^{5}$ based on an individual eye's keratometry and axial length, to estimate ELP. Indeed, it is well known that in eyes that have undergone corneal refractive surgery the pre-refractive surgery keratometry (pre-op Ks) may be unknown, rendering the predictability of the ELP problematic, thereby contributing to poor predictability of refractive outcomes following cataract surgery in such eyes. ${ }^{6}$ 
Ho et al, in 2008, described a regression-analysis derived form of the Fyodorov equation ${ }^{5}$ to calculate a theoretical corneal radius $\left(\mathrm{R}_{\mathrm{rt}}\right)$ which can be used to estimate the ELP, independently of preoperative keratometry readings. ${ }^{6}$

The Pentacam ${ }^{\circledR}$ (Oculus Optikgeräte GmBH, Wetzlar, Germany) is a rotating Scheimpflug camera designed to image the anterior segment. It provides topographic maps of the anterior and posterior corneal surfaces, pachymetry maps, and biometric measurements of the anterior segment. ${ }^{6-8}$

In this way, the Pentacam-measured anterior chamber diameter (measured from anterior chamber angle to anterior chamber angle, $\mathrm{AG}_{\mathrm{m}}$ ) and corneal height (measured from the internal cornea to the line connecting the anterior chamber angles, $\mathrm{H}_{\mathrm{m}}$ ) can be used to calculate the theoretical corneal radius $\left(\mathrm{R}_{\mathrm{rt}}\right){ }^{6}$ Ho et al reported that there was good agreement with this keratometry-independent ELP estimate when compared with traditional keratometry-dependent ELP estimation methods, using the Holladay 1 and SRK/T formulae. ${ }^{6}$ However, postoperative IOL position was not measured in the study by Ho et al, and therefore their conclusions were based solely upon estimation errors pre-cataract surgery. ${ }^{6}$

The keratometry-independent ELP methods, described by Ho et al, ${ }^{6}$ could represent an important advance in cataract surgery for patients who have had previous corneal refractive surgery. We will henceforth refer to this method as the keratometryindependent ELP estimation. We performed a study to compare keratometrydependent ELP estimation methods versus keratometry-independent ELP estimation methods.

\section{Methods}


We prospectively studied 95 cataractous eyes of 95 consecutive patients with no visually consequential ocular co-morbidity, all of whom underwent uneventful phacoemulsification cataract surgery between November 2008 and May 2009. Eyes with a history of trauma or ocular surgery were excluded. This study was approved by the South East Regional Ethics Committee, and the study protocol adhered to the tenets of the Declaration of Helsinki. Valid and informed consent was secured from each volunteer prior to enrolment. We certify that all applicable institutional and governmental regulations concerning the ethical use of human volunteers were followed during this research.

All patients underwent a complete ophthalmic examination including, automatic keratometry (IOLMaster ${ }^{\circledR}$ version 5 Carl Zeiss Ltd., Welwyn Garden City, UK), ocular biometry (IOLMaster® version 5 Carl Zeiss Ltd., Welwyn Garden City, UK), and a Pentacam scan.

In this study, the Pentacam system was set to acquire 25 images per scan at the automatic release mode (images captured automatically). To obtain the Pentacammeasured $\mathrm{H}_{\mathrm{m}}$, the Scheimpflug image in the horizontal meridian was displayed. The software (version 1.16) showed the locations of the anterior chamber angles. A line connecting the 2 points of the anterior chamber angles was drawn. Then, a line was drawn from the anterior corneal vertex, which intersected and was perpendicular to the line connecting the anterior chamber angles. The distance from the posterior corneal surface to the intersection point was termed $\mathrm{H}_{\mathrm{m}}$. The distance between the 2 anterior chamber angle points was termed $\mathrm{AG}_{\mathrm{m}}$ (the measured anterior chamber diameter from angle to angle, Figure 1). ${ }^{6}$ 
The Appendix outlines the equations used by Ho et al to estimate ELP using 4 different methods (Equations $2-5){ }^{6}$ Equation 1 is a formula for calculating the theoretical corneal radius $\left(\mathrm{R}_{\mathrm{rt}}\right)$, which is a substitute for keratometry in subsequent keratometry-independent formulae (Equations 3 and 5). ${ }^{6}$ Equation 2 describes a formula that estimates $\mathrm{ELP}_{\mathrm{s}}$, which is the ELP estimate obtained when using the SRK/T formula with keratometry in the traditional fashion. Equation 3 describes a formula that estimates $\mathrm{ELP}_{\mathrm{rs}}$, which is the ELP estimate obtained when using the SRK/T formula with the $\mathrm{R}_{\mathrm{rt}}$ used instead of keratometry. Equation 4 describes a formula that estimates $\operatorname{ELP}_{\mathrm{h}}$, which is the ELP estimate obtained when using the Holladay 1 formula with keratometry in the traditional fashion. Equation 5 describes a formula that estimates $\mathrm{ELP}_{\mathrm{rh}}$, which is the ELP estimate obtained when using the Holladay 1 formula with the $\mathrm{R}_{\mathrm{rt}}$ used instead of keratometry. The ELP was calculated for all study eyes, by the SRK/T and Holladay 1 formula using keratometrydependent (Equations 2 and 4) and keratometry-independent ELP estimation methods (Equations 3 and 5), respectively.

\section{Surgical procedures}

In each study eye, surgical procedures were performed under topical anaesthesia (proxymetacaine hydrochloride $0.5 \%$, Minims, Chauvin Pharmaceuticals, Surrey, UK). All operations were performed through a $2.75 \mathrm{~mm}$ superior clear corneal incision. A continuous curvilinear capsulorrhexis was completed following viscoelastic injection (Healon ${ }^{\circledR}$, Advanced Medical Optics Inc, Santa Ana, California, US), hydrodissection was performed using balanced salt solution (BSS, Alcon laboratories, Inc., UK). The irrigation solution contained $16 \%$ gentamicin sulphate (80mg Genticin ${ }^{\circledR}$ Roche, Welwyn Garden City, UK in 500ml BSS PLUS ${ }^{\circledR}$ surgical 
solution, Alcon laboratories, Inc., UK). After removal of the nucleus using torsional phaco-technology (Infiniti ${ }^{\circledR}$, Alcon laboratories, Inc., UK), irrigation and aspiration of soft lens matter was performed; then a foldable, posterior chamber intraocular lens (Tecnis ${ }^{\circledR}$ ZA9003, Advanced Medical Optics Inc, Santa Ana, California, US; AConstant 119.1; $\mathrm{ACD}_{\text {const }}$ 5.6; Surgeon Factor 1.85) was implanted in the capsular bag with an introducer (AMO EmeraldT Series Unfolder and Cartridge ${ }^{\circledR}$, Advanced Medical Optics Inc, Santa Ana, California, US). Stromal hydration was then performed to achieve wound integrity; a 10/0 Nylon suture was occasionally placed in the corneal wound when wound integrity was deemed inadequate by the surgeon. Intracameral cefuroxime (1mg Zinacef ${ }^{\mathrm{TM}}$, GlaxoSmithKline, UK, in $0.1 \mathrm{ml}$ of sterile water for injection, B. Braun Medical Inc., PA, US) was administered via the paracentesis. Then a single drop of $1 \%$ apraclonidine (Iopidine ${ }^{\circledR} 1 \%$, Alcon laboratories, Inc., UK) and an aliquot of $1 \%$ fucidic acid ointment (Fucithalmic ${ }^{\circledR}$ Leo Pharmaceutics, Ontario, Canada) was administered to the corneal surface.

\section{Postoperative examination}

The patient was examined two weeks postoperatively, and in cases where a corneal suture was in-situ, it was removed at this visit. The patient was then reexamined six weeks postoperatively, when postoperative IOL position was calculated, using the inbuilt calipers on the Pentacam screen (Figure 1); this was done because of the possible failure of the Pentacam to automatically identify the anterior surface of the $\mathrm{IOL}^{9}$.

\section{Statistical analysis}

Data were analysed by an Aabel software package (version 3.0.3, GigaWiz 
Ltd. Co., Tulsa, OK, USA). Agreement between the respective keratometrydependent and keratometry independent methods of ELP estimation is represented by Bland-Altman plots, and expressed in terms of mean bias \pm 1.96 standard deviations (SD). Correlations were calculated using Pearson's correlation coefficient (r) and a pvalue $<0.05$ was taken as statistically significant; the $r^{2}$ value is also documented for completeness.

We calculated the differences (arithmetic and absolute) between the ELP estimates using traditional keratometry-dependent and their respective and novel keratometry-independent estimation methods. This yielded the mean arithmetic estimation error (ME) and mean absolute estimation error (MAE). When using the SRK/T formula to calculate the $\mathrm{ELP}_{\mathrm{s}}$ and the $\mathrm{ELP}_{\mathrm{rs}}$, the $\mathrm{ME}_{\mathrm{s}}=$ mean $\mathrm{ELP}_{\mathrm{rs}}-$ mean $\mathrm{ELP}_{\mathrm{s}}$ and the $\mathrm{MAE}_{\mathrm{s}}=$ mean absolute $\mathrm{ELP}_{\mathrm{rs}}-$ mean absolute ELP . When using the Holladay 1 formula to calculate the $\mathrm{ELP}_{\mathrm{h}}$ and the $\mathrm{ELP}_{\mathrm{rh}}$, the $\mathrm{ME}_{\mathrm{h}}=$ mean $\mathrm{ELP}_{\mathrm{rh}}$ mean $\mathrm{ELP}_{\mathrm{h}}$ and the $\mathrm{MAE}_{\mathrm{h}}=$ mean absolute $\mathrm{ELP}_{\mathrm{rh}}-$ mean absolute $\mathrm{ELP}_{\mathrm{h}}$.

\section{Results}

The biometric data in 95 unoperated eyes (Table 1) were used to estimate the ELP using keratometry-dependent $\left(\mathrm{ELP}_{\mathrm{s}}\right.$ and $\left.\mathrm{ELP}_{\mathrm{h}}\right)$ and keratometry-independent methods $\left(\mathrm{ELP}_{\mathrm{rs}}\right.$ and $\left.\mathrm{ELP}_{\mathrm{rh}}\right)$. In our study, the mean $\mathrm{ELP}_{\mathrm{S}}( \pm \mathrm{SD})$ calculated using preoperative keratometry values in the SRK/T formula (Equation 2) was $5.59 \pm 0.52$ $\mathrm{mm}$, and was significantly and positively correlated with keratometry-independent 
$\operatorname{ELP}_{\mathrm{rs}}(5.55 \pm 0.42 \mathrm{~mm})\left(\mathrm{r}=0.781, \mathrm{r}^{2}=66.1 \%, \mathrm{P}<0.001\right.$, Figure 2$)$, when the $\mathrm{R}_{\mathrm{rt}}$ values were used in the SRK/T formula (Equation 3). Agreement between $\mathrm{ELP}_{\mathrm{s}}$ and $\mathrm{ELP}_{\mathrm{rs}}$ is represented by the Bland Altman plot in Figure 3, with a mean difference $( \pm$ 1.96 SD; range) of $0.06( \pm 0.65 ;-0.59$ to +0.71$) \mathrm{mm}$ in association with $\mathrm{ELP}_{\mathrm{rs}}$. The $\mathrm{ME}_{\mathrm{s}}$ for $\mathrm{ELP}_{\mathrm{s}}$ estimation versus $\mathrm{ELP}_{\mathrm{rs}}$ estimation was $0.061 \pm 0.241 \mathrm{~mm}$ (range: 0.589 to $1.272 \mathrm{~mm}$ ) and the $\mathrm{MAE}_{\mathrm{s}}$ for $\mathrm{ELP}_{\mathrm{s}}$ estimation versus $\mathrm{ELP}_{\mathrm{rs}}$ estimation was $0.242 \pm 0.222 \mathrm{~mm}$ (range: 0.001 to $1.272 \mathrm{~mm}$ ). Agreement between postoperative IOL position and ELP $_{\mathrm{rs}}$ is represented by the Bland Altman plot in Figure 4, with a mean difference $( \pm 1.96 \mathrm{SD}$; range $)$ of $1.22( \pm 0.82 ;+0.40$ to +2.04$) \mathrm{mm}$ in association with $\mathrm{ELP}_{\mathrm{rs}}$.

The mean $\mathrm{ELP}_{\mathrm{h}}( \pm \mathrm{SD})$ calculated using preoperative keratometry readings in the Holladay 1 formula (Equation 4) was $5.63 \pm 0.42 \mathrm{~mm}$, and was significantly and positively correlated with keratometry-independent $\operatorname{ELP}_{\mathrm{rh}}(5.60 \pm 0.36 \mathrm{~mm})(\mathrm{r}=$ $0.874, r^{2}=76.4 \%, P<0.001$, Figure 5), when the preoperative $R_{r t}$ values were used in the Holladay 1 formula (Equation 5). Agreement between $\operatorname{ELP}_{\mathrm{h}}$ and $\mathrm{ELP}_{\mathrm{rh}}$ is represented by the Bland Altman plot in Figure 6, with a mean difference $( \pm 1.96 \mathrm{SD}$; range) of $-0.04( \pm 0.39 ;-0.43$ to +0.35$) \mathrm{mm}$ in association with $\mathrm{ELP}_{\mathrm{rh}}$. The mean arithmetic estimation error $\left(\mathrm{ME}_{\mathrm{h}}=\right.$ mean $\mathrm{ELP}_{\mathrm{rh}}-$ mean $\left.\mathrm{ELP}_{\mathrm{h}}\right)$ was $-0.037 \pm 0.203 \mathrm{~mm}$ (range: -0.814 to $0.417 \mathrm{~mm})$ and the mean absolute error $\left(\mathrm{MAE}_{\mathrm{h}}=\right.$ mean absolute $\mathrm{ELP}_{\mathrm{rh}}$ - mean absolute $\mathrm{ELP}_{\mathrm{h}}$ ) was $0.152 \pm 0.137 \mathrm{~mm}$ (range: 0.001 to $0.814 \mathrm{~mm}$ ). Agreement between the postoperative IOL position and ELP $\mathrm{rh}_{\mathrm{rh}}$ is represented by the Bland Altman plot in Figure 7, with a mean difference ( \pm 1.96 SD; range) of $1.27( \pm$ $0.73 ;+0.54$ to +2.00$) \mathrm{mm}$ in association with $\mathrm{ELP}_{\mathrm{rh}}$.

\section{Discussion}


The relationship between ELP calculated using keratometry-dependent and keratometry-independent methods is positive and significant, and agreement between the two techniques is good, and we could expect clinically comparable refractive outcomes following cataract surgery using keratometry-independent and keratometry-dependent methods of ELP estimation.

The $\mathrm{ME}_{\mathrm{s}}$ and $\mathrm{ME}_{\mathrm{h}}$ were slightly greater in our study $(0.061 \pm 0.241 \mathrm{~mm}$ and $0.037 \pm 0.203 \mathrm{~mm}$, respectively) than those reported by Ho et al $(-0.011 \pm 0.263 \mathrm{~mm}$ and $-0.0004 \pm 0.167 \mathrm{~mm}$, respectively) ${ }^{6}$, but are broadly comparable to those reported in the former study, that generated equations 1,3 and 5 by regression analysis from the data in their own study (thus explaining the better agreement that they report). It is interesting to note that, in our study, when the SRK/T formulae employs keratometryindependent methods to calculate the ELP $\left(\operatorname{ELP}_{\mathrm{rs}}\right)$, it exhibited a slight tendency towards overestimation (and consequential hyperopic shift) relative to keratometrydependent ELP estimation methods $\left(\mathrm{ELP}_{\mathrm{s}}\right)$, in contrast to slight underestimation in the Ho study ${ }^{6}$. However, ELP rh yielded a slight underestimation (and consequential myopic shift) in both studies ${ }^{6}$. The mean absolute errors of ELP estimation reported in our study (ELP $P_{\mathrm{rs}}: 0.242 \mathrm{~mm}$; $\left.\mathrm{ELP}_{\mathrm{rh}}: 0.152 \mathrm{~mm}\right)$ are less than half the distance between a sulcus-positioned IOL and an IOL implanted in the capsular bag (approximately $0.75 \mathrm{~mm}){ }^{10}$ which results in a $1.05 \mathrm{D}$ difference in the IOL plane,${ }^{10}$ equivalent to 0.78 $\mathrm{D}$ in the spectacle plane. ${ }^{10}$ This is consistent with the findings of Olsen et al, who reported that a $0.1 \mathrm{~mm}$ difference in postoperative IOL position corresponded to a $0.14 \mathrm{D}$ change in power in the IOL plane. ${ }^{11}$ 
In our study, the approximate mean and maximum discrepancies in the IOL plane were $0.34 \mathrm{D}$ and $1.78 \mathrm{D}$ for $\operatorname{ELP}_{\mathrm{rs}}$ (mean discrepancy $=\mathrm{MAE}_{\mathrm{s}} \times 1.4$; maximum discrepancy $=$ maximum absolute error of ELP $x$ 1.4). In terms of the discrepancy in the spectacle plane (discrepancy in IOL plane x 0.743 ) ${ }^{10}$ this would be represented by estimated mean and maximum discrepancies of $0.25 \mathrm{D}$ and 1.32 D, respectively. Similarly the approximate mean and maximum discrepancies in the IOL plane were $0.21 \mathrm{D}$ and $1.14 \mathrm{D}$ for $\mathrm{ELP}_{\mathrm{rh}}$ (mean discrepancy $=\mathrm{MAE}_{\mathrm{h}} \mathrm{x}$ 1.4; maximum discrepancy $=$ maximum absolute error of $\left.E P_{h} \times 1.4\right)^{11}$. In terms of the discrepancy in the spectacle plane, this would be represented by estimated mean and maximum discrepancies of $0.16 \mathrm{D}$ and $0.84 \mathrm{D}$, respectively.

With regard to the $\mathrm{ELP}_{\mathrm{rs}}$, the calculated discrepancy in the spectacle plane between keratometry-dependent and keratometry-independent estimation methods was: $<0.5 \mathrm{D}$ in $90.5 \%$ of cases; $<1.0 \mathrm{D}$ in $97.9 \%$ of cases: $<2.0 \mathrm{D}$ in $100 \%$ of cases. With regard to the $\mathrm{ELP}_{\mathrm{rh}}$, the calculated discrepancy in the spectacle plane between keratometry-dependent and keratometry-independent estimation methods was: $<0.5$ $\mathrm{D}$ in $96.8 \%$ of cases; < $1.0 \mathrm{D}$ in $100 \%$ of cases.

In our study, the mean postoperative manifest refraction spherical equivalent (MRSE) prediction error was $0.51 \pm 0.45 \mathrm{D}$ (range -1.95 to $+1.16 \mathrm{D}$; where $66.3 \%$ were $<0.5$ D; $87.4 \%$ were $<1.0 \mathrm{D} ; 100 \%$ were $<2.0 \mathrm{D})$. These results compare favourably with other studies looking at the mean postoperative MRSE prediction error following phacoemulsification cataract surgery, in which the mean postoperative MRSE prediction error is reported as follows: $45.5 \%$ to $92.0 \%$ of cases were $<0.5 \mathrm{D}^{12-21}$ and $41 \%$ to $100 \%$ of cases were $<1.0$ D. ${ }^{12-21}$ In our study, the calculated discrepancies in 
the spectacle plane between keratometry-dependent and keratometry-independent estimation methods using either SRK/T or Holladay 1, are less than our mean postoperative MRSE prediction errors and also compare favourably with typically reported mean postoperative MRSE prediction errors in the literature. ${ }^{12-21}$ These calculated discrepancies also compare favourably with studies of patients undergoing phacoemulsification cataract surgery, who have previously undergone laser in-situ keratomileusis (LASIK), where it is reported that between $13 \%$ and $67 \%$ of patients had a reported mean postoperative MRSE within $0.5 \mathrm{D}$ of target, that between $25 \%$ and $100 \%$ had a reported mean postoperative mean postoperative MRSE within $1.0 \mathrm{D}$ of target, and that between $79 \%$ and $100 \%$ had a reported mean postoperative mean postoperative MRSE within $2.0 \mathrm{D}$ of target.$^{22-24}$

Possible sources of the slightly differing results between our study and that of Ho et al, in terms of ELP, may result from differences in terms of age and axial length between the two sample populations. Our sample had a mean age $( \pm$ SD) of $70.2( \pm$ 10.7) years, over double that of Ho et al's sample at $34.4( \pm 16.1)$ years; ${ }^{6}$ given that ELP is positively correlated with age (ELP increases with age $)^{4}$, this may account for the slight tendency towards overestimation with the SRK/T keratometry-independent ELP estimation method in our study, when compared with that of Ho et al. ${ }^{6}$ However, this relationship between ELP and age fails to explain the observed discrepancy between the slight underestimation seen when using the Holladay 1 keratometryindependent ELP estimation method in our study, when compared with that of Ho et al. $^{6}$

While our sample was less myopic, with a mean spherical equivalent of -0.89 $( \pm 4.54) \mathrm{D}$, compared with that of Ho et al's of $-5.84( \pm 3.92) \mathrm{D},{ }^{6}$ and this is reflected 
further in the differing axial lengths of the two studies [mean \pm SD: current study: $23.88( \pm 1.80) \mathrm{mm}$; Ho et al: $25.73( \pm 1.59) \mathrm{mm}],{ }^{6}$ it has been shown that estimates of ELP are independent of preoperative refractive error, ${ }^{325}$ but correlate positively with axial length. ${ }^{325}$ In a study looking at the accuracy of prediction of refractive outcomes following cataract surgery using various formulae including SRK/T and Holladay 1, Narvaez et al found a similar trend (which did not reach statistical significance), reflected in varying refractive outcomes (range of MAE: 0.02 to $0.10 \mathrm{D}$ ) postphacoemulsification cataract surgery between groups of eyes of differing axial lengths, ${ }^{18}$ and the observed discrepancy is similar in order of magnitude to the discrepancy between our study and that of Ho et al. ${ }^{6}$ In spite of the differences in population samples, however, it is noteworthy that the keratometry-independent ELP method appears to be relatively robust, with comparable estimation errors $\left(\mathrm{ME}_{\mathrm{s}}, \mathrm{ME}_{\mathrm{h}}\right.$, $\mathrm{MAE}_{\mathrm{s}}$ and $\mathrm{MAE}_{\mathrm{h}}$ ) in both studies.

We compared this novel method of keratometry-independent ELP estimation with the existing keratometry-dependent ELP methods, but also with the anatomic postoperative IOL position, and this relationship has never been previously investigated for the SRK/T and Holladay 1 formulae. We found that the ELP was significantly greater than the anatomic postoperative IOL position by a mean difference of $1.27 \mathrm{~mm}(\mathrm{p}<0.001$; student's paired t-test). This is in agreement with the theoretical model proposed by Holladay et al. ${ }^{26}$ It is worth noting that, despite this discrepancy, the ELP $\left(\operatorname{ELP}_{\mathrm{rs}}\right.$ and ELP $\left._{\mathrm{rh}}\right)$ was significantly and positively correlated with the postoperative IOL position. Jin et al, in a study designed to predict postoperative IOL position using formulae different to those in our study (Haigis algorithm; $r=0.6$; and Olsen 2 algorithm $r=0.46),{ }^{27}$ report similar levels of correlation to those seen in our study (postoperative IOL position versus ELP $_{\mathrm{rs}}: \mathrm{r}=$ 
0.43 and postoperative IOL position versus $\left.\mathrm{ELP}_{\mathrm{rh}}: \mathrm{r}=0.48\right)$. Although this correlation reached significance ( $\mathrm{p}<0.01$ for both methods in our study), the observed correlations between postoperative IOL position and ELP are simply not strong enough in themselves for reliable prediction of postoperative IOL position. ${ }^{27}$

Refractive laser surgery alters corneal thickness and keratometry, but does not alter ACD or corneal height measured form the endothelial surface $\left(\mathrm{H}_{\mathrm{m}}\right){ }^{28} \mathrm{It}$ follows, therefore, that a method of ELP estimation, where the required biometric parameters are unchanged by refractive laser surgery, such as the keratometry-independent ELP estimation method described here, would be extremely useful in post-refractive patients contemplating cataract surgery.

As there were only 11 post-refractive surgery patients undergoing cataract surgery in Ho et al's paper, ${ }^{6}$ our results would support the view that this novel keratometry-independent ELP estimation method appears to have the validity to warrant formal testing, in the form of a concordance study with existing keratometrydependent methods ${ }^{6}{ }^{29}$, in the context of a large cohort of patients scheduled for cataract surgery, but who have undergone prior refractive laser surgery. 


\section{References:}

1. Holladay JT, Prager TC, Chandler TY, Musgrove KH, Lewis JW, Ruiz RS. A threepart system for refining intraocular lens power calculations. J Cataract Refract Surg 1988;14(1):17-24.

2. Holladay JT, Prager TC, Ruiz RS, Lewis JW, Rosenthal H. Improving the predictability of intraocular lens power calculations. Arch Ophthalmol 1986;104(4):539-41.

3. Olsen T. Prediction of the effective postoperative (intraocular lens) anterior chamber depth. J Cataract Refract Surg 2006;32(3):419-24.

4. Olsen T. Calculation of intraocular lens power: a review. Acta Ophthalmol Scand 2007;85(5):472-85.

5. Fyodorov SN, Galin MA, Linksz A. Calculation of the optical power of intraocular lenses. Invest Ophthalmol 1975;14(8):625-8.

6. Ho JD, Liou SW, Tsai RJ, Tsai CY. Estimation of the effective lens position using a rotating Scheimpflug camera. J Cataract Refract Surg 2008;34(12):211927.

7. Lackner B, Schmidinger G, Pieh S, Funovics MA, Skorpik C. Repeatability and reproducibility of central corneal thickness measurement with Pentacam, Orbscan, and ultrasound. Optom Vis Sci 2005;82(10):892-9.

8. Barkana Y, Gerber Y, Elbaz U, Schwartz S, Ken-Dror G, Avni I, et al. Central corneal thickness measurement with the Pentacam Scheimpflug system, optical low-coherence reflectometry pachymeter, and ultrasound pachymetry. J Cataract Refract Surg 2005;31(9):1729-35.

9. Su PF, Lo AY, Hu CY, Chang SW. Anterior chamber depth measurement in phakic and pseudophakic eyes. Optom Vis Sci 2008;85(12):1193-200.

10. Suto C, Hori S, Fukuyama E, Akura J. Adjusting intraocular lens power for sulcus fixation. J Cataract Refract Surg 2003;29(10):1913-7.

11. Olsen T. Sources of error in intraocular lens power calculation. J Cataract Refract Surg 1992;18(2):125-9.

12. Kugelberg $M$, Lundstrom $M$. Factors related to the degree of success in achieving target refraction in cataract surgery: Swedish National Cataract Register study. J Cataract Refract Surg 2008;34(11):1935-9.

13. Eleftheriadis H. IOLMaster biometry: refractive results of 100 consecutive cases. Br J Ophthalmol 2003;87(8):960-3.

14. Gale RP, Saldana M, Johnston RL, Zuberbuhler B, McKibbin M. Benchmark standards for refractive outcomes after NHS cataract surgery. Eye (Lond) 2009;23(1):149-52.

15. Haigis W. [IOL calculation for high ametropia]. Ophthalmologe 2008;105(11):999-1004.

16. MacLaren RE, Natkunarajah M, Riaz Y, Bourne RR, Restori M, Allan BD. Biometry and formula accuracy with intraocular lenses used for cataract surgery in extreme hyperopia. Am J Ophthalmol 2007;143(6):920-31.

17. MacLaren RE, Sagoo MS, Restori M, Allan BD. Biometry accuracy using zeroand negative-powered intraocular lenses. J Cataract Refract Surg 2005;31(2):280-90. 
18. Narvaez J, Zimmerman G, Stulting RD, Chang DH. Accuracy of intraocular lens power prediction using the Hoffer Q, Holladay 1, Holladay 2, and SRK/T formulas. J Cataract Refract Surg 2006;32(12):2050-3.

19. Olsen T. Improved accuracy of intraocular lens power calculation with the Zeiss IOLMaster. Acta Ophthalmol Scand 2007;85(1):84-7.

20. Packer M, Fine IH, Hoffman RS, Coffman PG, Brown LK. Immersion A-scan compared with partial coherence interferometry: outcomes analysis. J Cataract Refract Surg 2002;28(2):239-42.

21. Rajan MS, Keilhorn I, Bell JA. Partial coherence laser interferometry vs conventional ultrasound biometry in intraocular lens power calculations. Eye (Lond) 2002;16(5):552-6.

22. Diehl JW, Yu F, Olson MD, Moral JN, Miller KM. Intraocular lens power adjustment nomogram after laser in situ keratomileusis. J Cataract Refract Surg 2009;35(9):1587-90.

23. Awwad ST, Kelley PS, Bowman RW, Cavanagh HD, McCulley JP. Corneal refractive power estimation and intraocular lens calculation after hyperopic LASIK. Ophthalmology 2009;116(3):393-400 e1.

24. Awwad ST, Manasseh C, Bowman RW, Cavanagh HD, Verity S, Mootha V, et al. Intraocular lens power calculation after myopic laser in situ keratomileusis: Estimating the corneal refractive power. J Cataract Refract Surg 2008;34(7):1070-6.

25. Holladay JT. Refractive power calculations for intraocular lenses in the phakic eye. Am J Ophthalmol 1993;116(1):63-6.

26. Holladay JT, Maverick KJ. Relationship of the actual thick intraocular lens optic to the thin lens equivalent. Am J Ophthalmol 1998;126(3):339-47.

27. Jin $\mathrm{H}$, Rabsilber $\mathrm{T}$, Ehmer A, Borkenstein AF, Limberger IJ, Guo H, et al. Comparison of ray-tracing method and thin-lens formula in intraocular lens power calculations. J Cataract Refract Surg 2009;35(4):650-62.

28. Rosa N, Lanza M, Capasso L, Lucci M, Polito B, Romano A. Anterior chamber depth measurement before and after photorefractive keratectomy: comparison between IOL master and Orbscan II. Ophthalmology 2006;113(6):962-9.

29. Aramberri J. Intraocular lens power calculation after corneal refractive surgery: double-K method. J Cataract Refract Surg 2003;29(11):2063-8. 


\section{Titles and legends to figures}

Figure 1. Scheimpflug image from the Pentacam, showing the distance from the posterior corneal surface of the vertex to the line connecting the anterior chamber angles was termed $\mathrm{H}_{\mathrm{m}}$. The distance between the 2 anterior chamber angle points was termed $\mathrm{AG}_{\mathrm{m}}$.

Figure 2. Scattergram of the effective lens position (ELP) estimate obtained when using the SRK/T formula in a keratometry-dependent method $\left(\mathrm{ELP}_{\mathrm{s}}\right)$ versus the ELP estimate obtained when using the SRK/T formula with the theoretical corneal radius $\left(R_{r t}\right)$ in a keratometry-independent method $\left(\operatorname{ELP}_{\mathrm{rs}}\right)$. Line of agreement is shown $(y=1 x+0)$.

Figure 3. Bland Altman plot of the difference between the effective lens position (ELP) estimate obtained when using the SRK/T formula in a keratometry-dependent method $\left(\mathrm{ELP}_{\mathrm{s}}\right)$ and the ELP estimate obtained when using the SRK/T formula with the theoretical corneal radius $\left(\mathrm{R}_{\mathrm{rt}}\right)$ in a keratometry-independent method $\left(\mathrm{ELP}_{\mathrm{rs}}\right)$. Line of mean difference (dotted line) and limits of \pm 1.96 standard deviations (unbroken line) are shown.

Figure 4 Bland Altman plot of the difference between the post-op intraocular lens (IOL) position and the effective lens position estimate obtained when using the SRK/T formula with the theoretical corneal radius $\left(\mathrm{R}_{\mathrm{rt}}\right)$ used instead of keratometry $\left(\mathrm{ELP}_{\mathrm{rs}}\right)$. Line of mean difference (dotted line) and limits of \pm 1.96 standard deviations (unbroken line) are shown.

Figure 5 Scattergram of the effective lens position (ELP) estimate obtained when using the Holladay 1 formula in a keratometry-dependent method $\left(\mathrm{ELP}_{\mathrm{h}}\right)$ versus 
the ELP estimate obtained when using the Holladay 1 formula with the theoretical corneal radius $\left(\mathrm{R}_{\mathrm{rt}}\right)$ in a keratometry-independent method $\left(\mathrm{ELP}_{\mathrm{rh}}\right)$. Line of agreement is shown $(y=1 x+0)$.

Figure 6 Bland Altman plot of the difference between the effective lens position estimate obtained when using the Holladay 1 formula with keratometry in the traditional fashion $\left(\mathrm{ELP}_{\mathrm{h}}\right)$ and the effective lens position estimate obtained when using the Holladay 1 formula with the theoretical corneal radius $\left(\mathrm{R}_{\mathrm{rt}}\right)$ used instead of keratometry $\left(\mathrm{ELP}_{\mathrm{rh}}\right)$. Line of mean difference (dotted line) and limits of \pm 1.96 standard deviations (unbroken line) are shown.

Figure 7 Bland Altman plot of the difference between the post-op intraocular lens (IOL) position and the effective lens position estimate obtained when using the Holladay 1 formula with the theoretical corneal radius $\left(\mathrm{R}_{\mathrm{rt}}\right)$ used instead of keratometry $\left(\mathrm{ELP}_{\mathrm{rh}}\right)$. Line of mean difference (dotted line) and limits of \pm 1.96 standard deviations (unbroken line) are shown. 
Effective lens position estimation utilising a keratometry-independent method, compares favourably with existing methods, and could potentially be utilised in postrefractive surgery intraocular lens calculation. 
Click here to download high resolution image

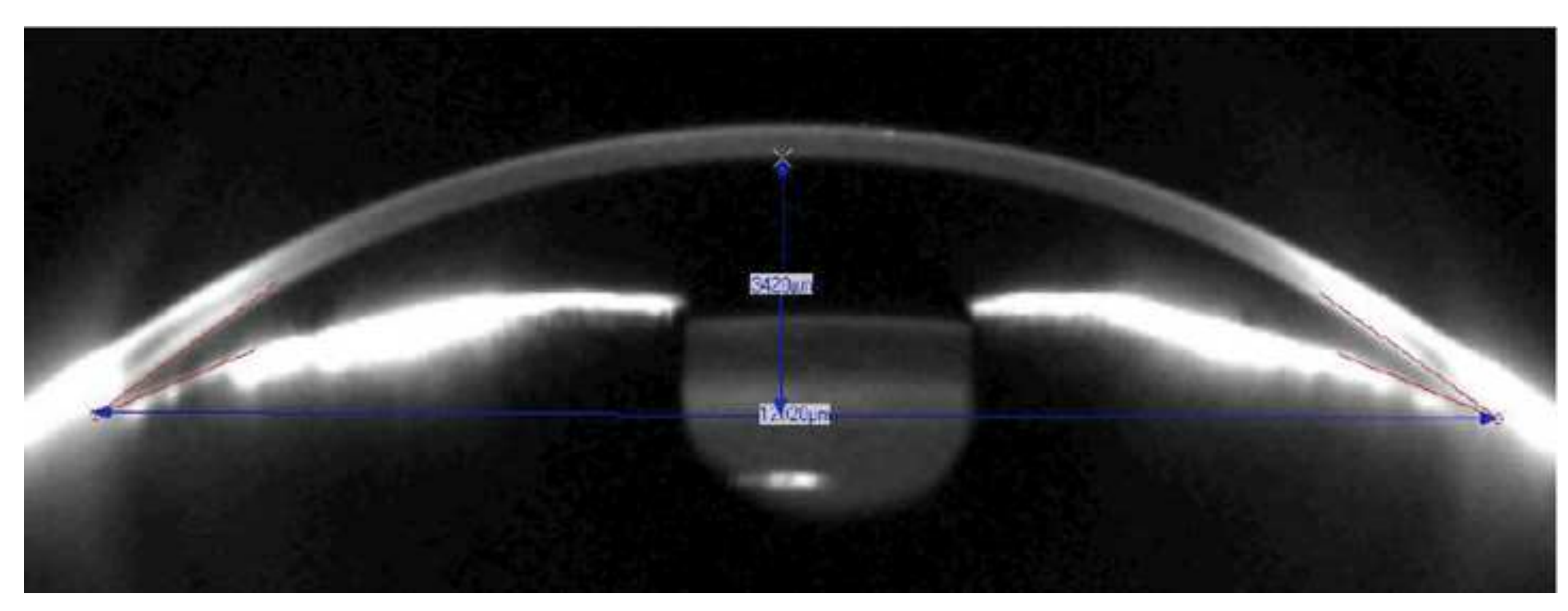

Click here to download high resolution image 


\section{ELPs versus ELPrs}

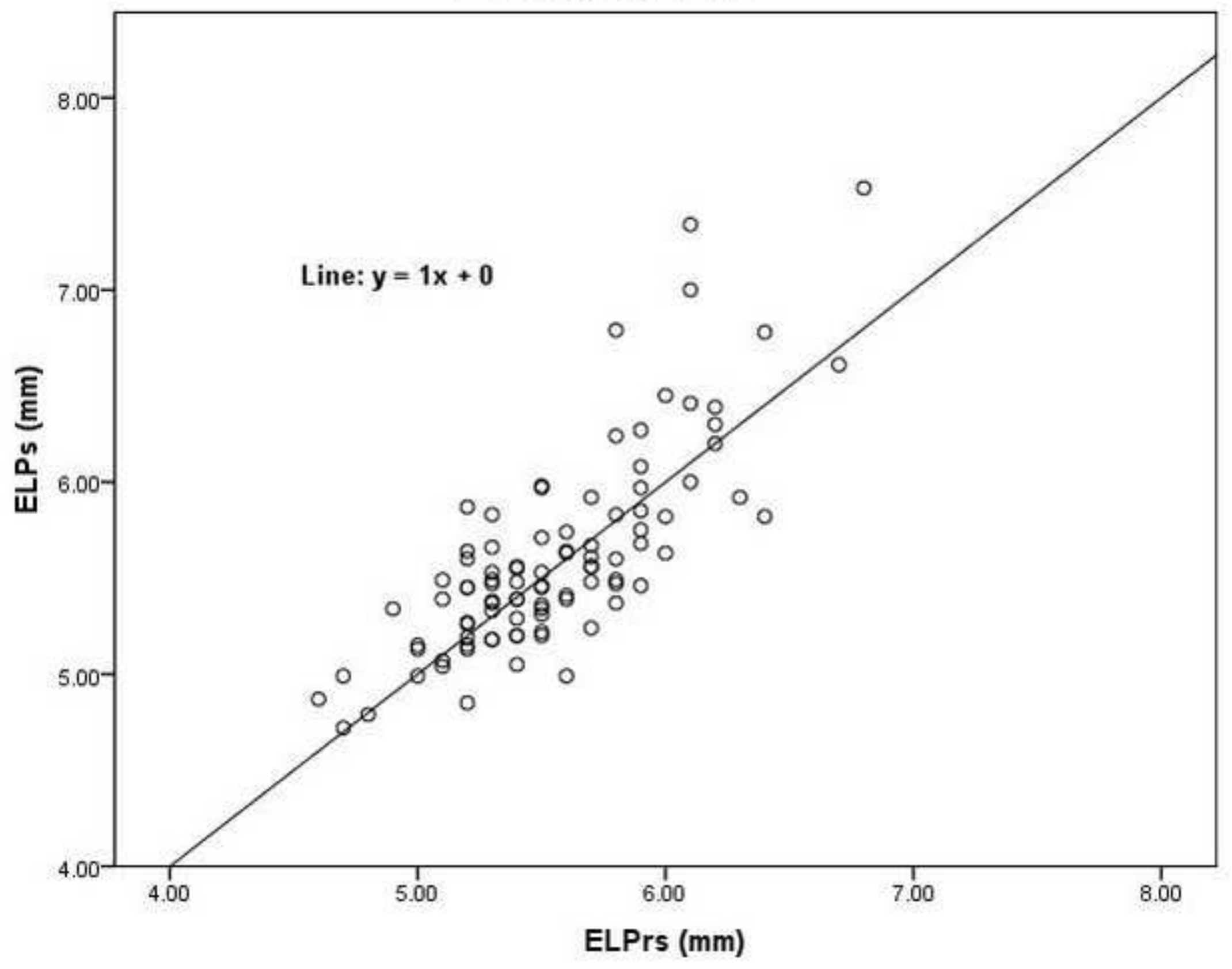


Click here to download high resolution image

- Group: 1

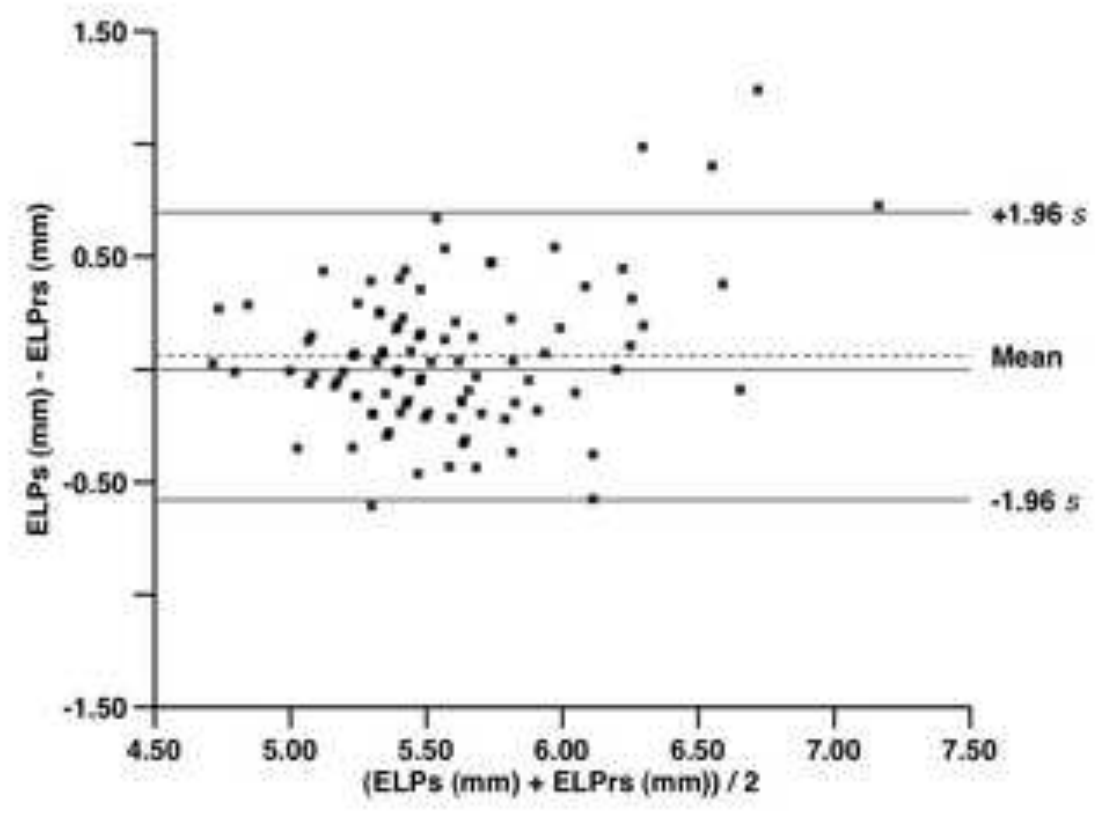


Figure 4
Click here to download high resolution image

- Group 1

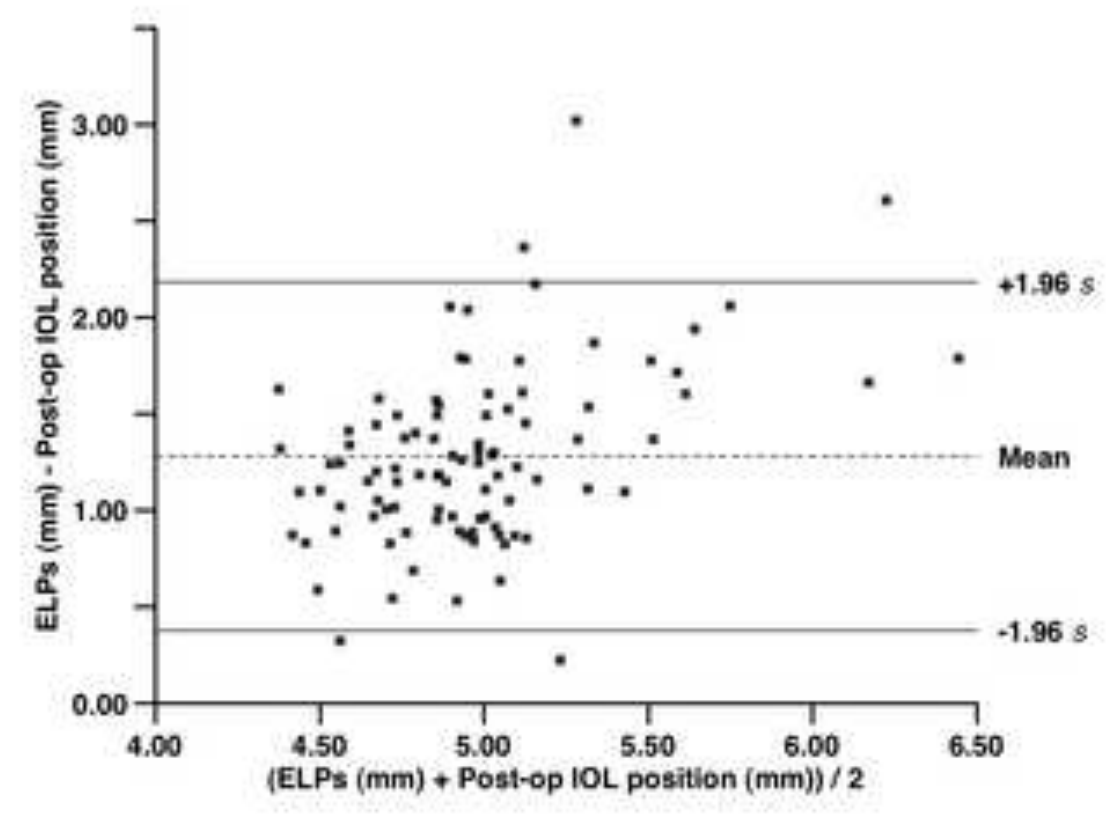




\section{ELPh versus ELPrh}

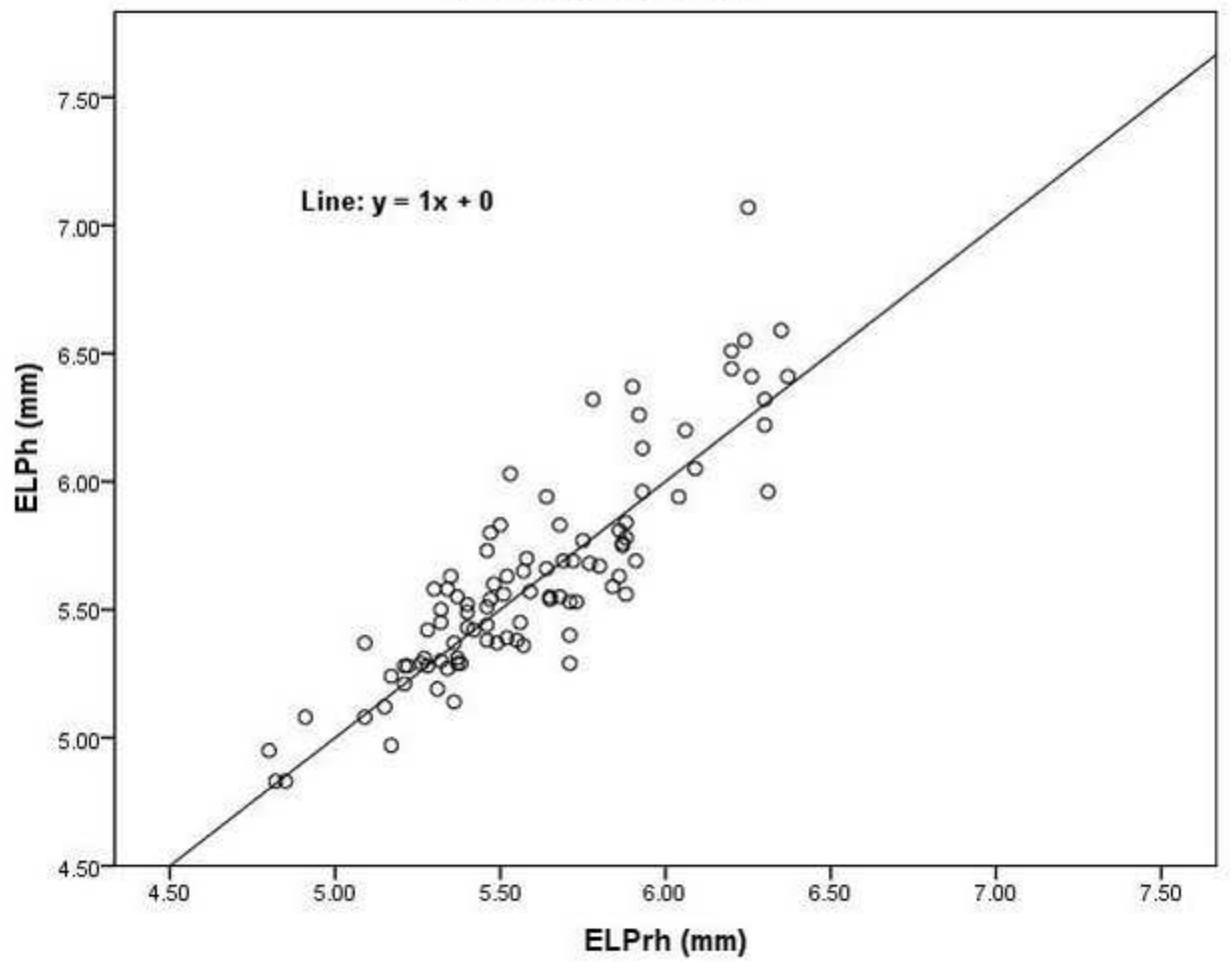


Figure 6
Click here to download high resolution image

- Groupi 1

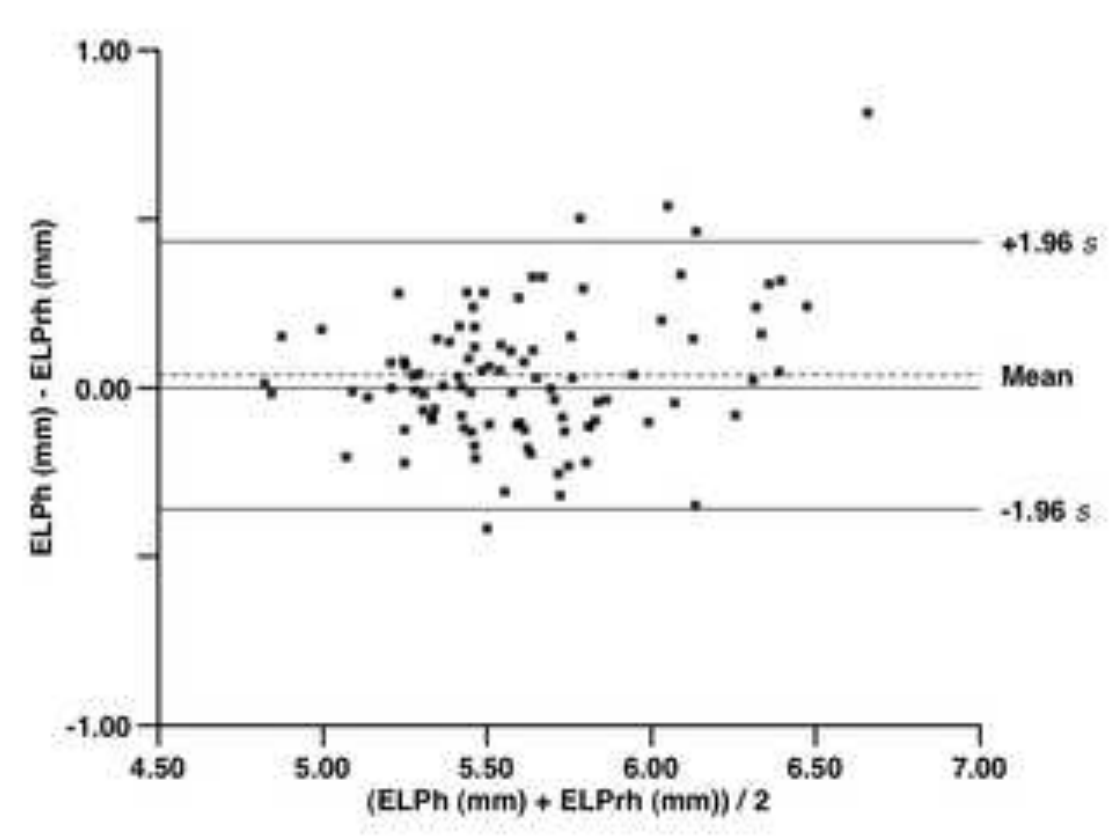


Click here to download high resolution image

- Group: 1

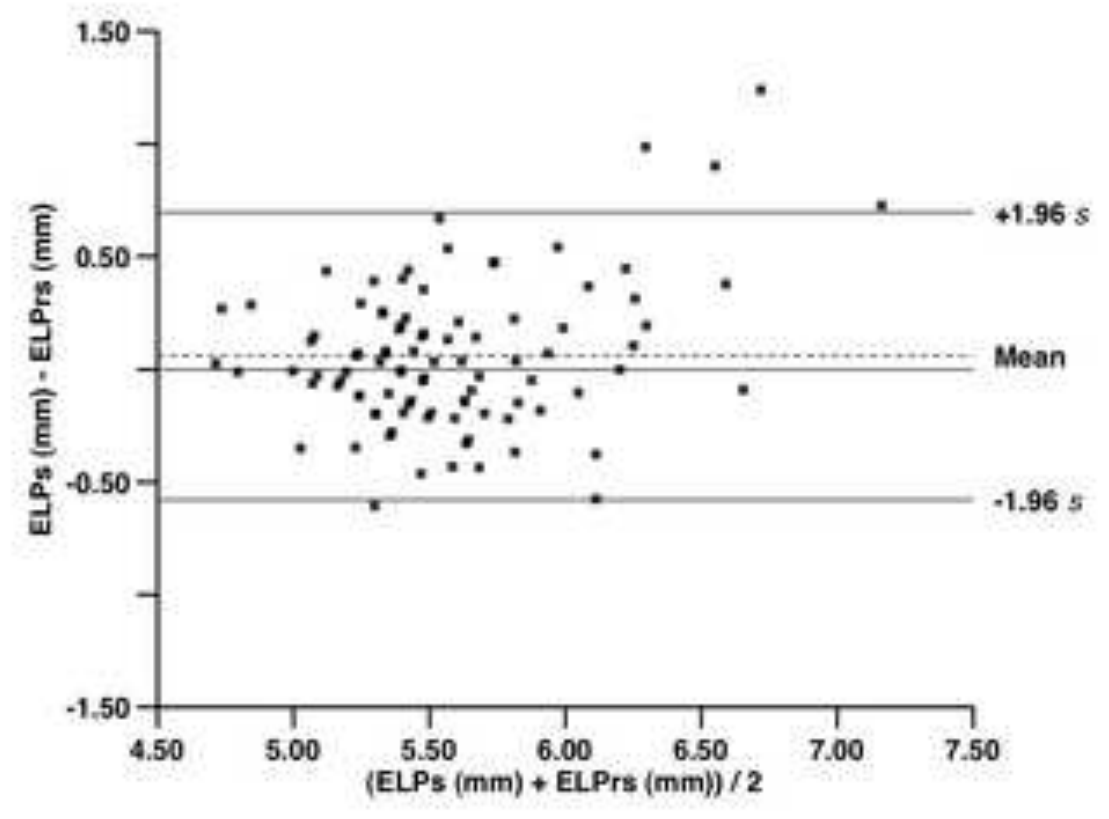


Table 1. Characteristics of the 95 virgin eyes used to develop formulas to derive the effective lens position, (ELP) using keratometry-dependent and keratometryindependent methods. Mean values, standard deviations (SD) and ranges are shown. $\mathrm{AG}_{\mathrm{m}}=$ Pentacam-measured anterior chamber diameter from angle to angle; $\mathrm{H}_{\mathrm{m}}=$ Pentacam-measured corneal height; $\mathrm{mm}=$ millimeters .

\begin{tabular}{lll}
\hline Characteristic & Mean \pm SD & Range \\
\hline Age (years) & $70.2 \pm 10.7$ & 38 to 88 \\
Spherical equivalent (Dioptres) & $-0.89 \pm 4.54$ & -20.38 to +7.63 \\
Anterior corneal radius $(\mathrm{mm})$ & $7.79 \pm 0.30$ & 7.25 to 8.25 \\
Axial length $(\mathrm{mm})$ & $23.88 \pm 1.80$ & 20.66 to 30.50 \\
$\mathrm{H}_{\mathrm{m}}(\mathrm{mm})$ & $3.49 \pm 0.37$ & 2.34 to 4.41 \\
$\mathrm{AG}_{\mathrm{m}}(\mathrm{mm})$ & $11.74 \pm 0.74$ & 9.51 to 13.71 \\
\hline
\end{tabular}



Appendix
Click here to download Supplementary Material: Appendix ELP July 7th 1.doc

Click here to download Supplementary Material: Appendix ELP July 7 th 1.doc (4)

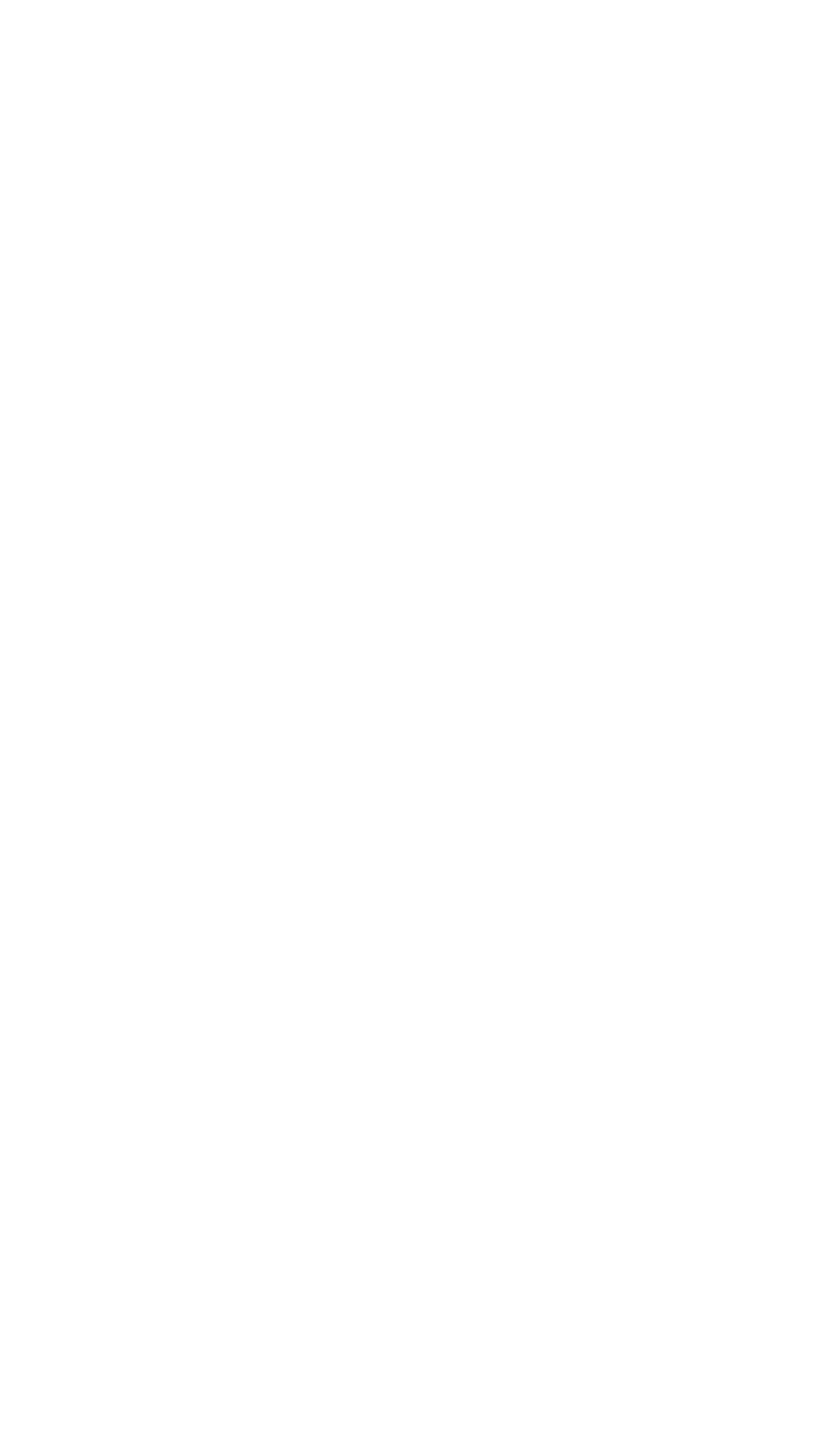


Author Photograph

Click here to download high resolution image

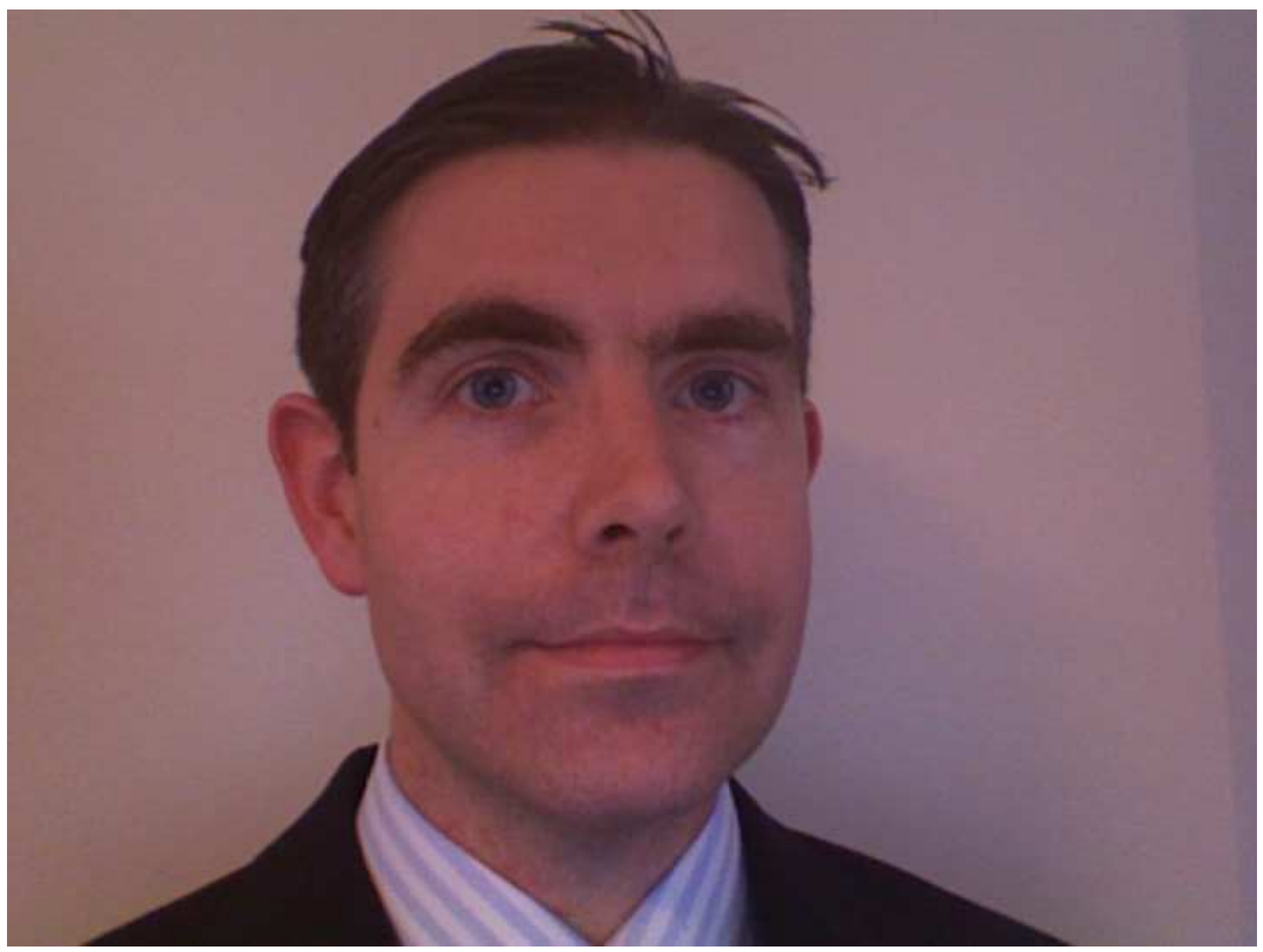


To: Emanuel S. Rosen, FRCSE

Nick Mamalis, MD

Editors: JCRS

Dr. Ian Dooley

173 The Grange

Raheen

Limerick

Ireland.

0868555993

iandooley@eustace.net

July 7, 2010

Dear Sirs,

I would appreciate you opinion regarding my original article, entitled:

"Estimation of effective lens position using a method independent of preoperative keratometry readings." I would be most grateful, if you would please consider this work for publication in the highly esteemed Journal of Cataract and Refractive Surgery.

Sincerely,

Dr. Ian Dooley MRCOphth 